\title{
PROPOSTA DE UTILIZAÇÃO DO MARKETING DIGITAL PARA CAPTAÇÃO DE CLIENTES NO ASCENDIMENTO DA E-COMMERCE NO RAMO ERÓTICO EM 2021: ESTUDO DE CASO NA HOT SECRETS
}

\section{ARTIGO ORIGINAL}

FEITOZA, Tharcya Lima1', FERNANDES, Andressa Karoline², DIDIER, Gustavo Santos $^{3}$, ALMEIDA, Victor da Silva ${ }^{4}$, SANTOS JÚNIOR, Aldemir Pereira dos ${ }^{5}$, ROBERTO, José Carlos Alves ${ }^{6}$

FEITOZA, Tharcya Lima. Et al. Proposta de utilização do marketing digital para captação de clientes no ascendimento da e-commerce no ramo erótico em 2021: estudo de caso na Hot Secrets. Revista Científica Multidisciplinar Núcleo do Conhecimento. Ano. 06, Ed. 11, Vol. 13, pp. 113-134. Novembro de 2021. ISSN: 2448-0959, Link de acesso: https://www.nucleodoconhecimento.com.br/administracao/captacao-declientes, DOI: 10.32749/nucleodoconhecimento.com.br/administracao/captacao-declientes

\section{RESUMO}

A ascensão das tecnologias tem proporcionado para as empresas diversas ferramentas para manter o relacionamento direto com seus clientes, criando assim, vínculos de fidelidade com seus consumidores, através da utilização de estratégias

\footnotetext{
${ }^{1}$ Graduanda do curso de Administração.

${ }^{2}$ Graduanda do curso de Administração.

${ }^{3}$ Graduando do curso de Administração.

${ }^{4}$ Coorientador. Mestre em Engenharia de Processos. Pós-Graduando em Neuropsicopedagogia Institucional. Especialista em Gestão Estratégica de RH. Graduado em Administração e Pedagogia.

${ }^{5}$ Coorientador. Mestre em Ciências do Ambiente e Sustentabilidade na Amazônia. Especialista em Gestão dos Recursos Naturais e Meio Ambiente. Especialista em Metodologia do Ensino Superior. Graduado em Turismo e Administração.

${ }^{6}$ Orientador. Mestre em Engenharia de produção. Especialista Logística empresarial. Graduado em Administração com Ênfase em Marketing.
}

RC: 102101

Disponível em: https://www.nucleodoconhecimento.com.br/administracao/captacaode-clientes 
adequadas de marketing digital. As redes sociais proporcionaram para as empresas uma nova forma de divulgar suas marcas e serviços prestados, de forma rápida e precisa, se tornando um meio de comunicação. Tendo em vista este cenário, o presente artigo, tem como questão norteadora: Como o marketing digital e de conteúdo podem ser importantes no aumento de clientes e lucratividade de uma $e$ commerce em ascensão? Diante dessa realidade, o presente artigo teve como objetivo determinar as estratégias de marketing mais viáveis o aumento do consumo de produtos eróticos nas plataformas digitais na empresa pesquisada, selecionando as melhores estratégias, expandindo o engajamento, a busca de produtos eróticos e a lucratividade de e-commerce eróticos. Para entender como o marketing digital e interativo estão influenciando, realizou-se uma explanação acerca do assunto proposto, e, posteriormente, foi utilizado para coleta de dados, as bibliografias, aplicando um estudo de caso e modelos de pensamento para obtenção de informações sobre o assunto proposto. Por fim, conclui-se que as estratégias de marketing digital, se aplicadas e associadas a ações de melhoria de conteúdo e uso de marketplaces, favorece não somente as e-commerces do ramo eróticos, mas também às novas em ascensão na captação e fidelização de novos clientes, tornando esse nicho de mercado mais atrativo.

Palavras-chave: Ascensão, Marketing digital, E-commerce, Erótico, Estratégias.

\section{INTRODUÇÃO}

A realização deste artigo utilizou como base os dados coletados na empresa Gustavo Santos Didier Eirelli, por diversas vezes citado como Hot Secrets, nome utilizado em sua e-commerce, que atua no ramo erótico em Manaus, e até o final da pesquisa trabalhava apena com vendas online.

Por ser inserida no ambiente Web, esperava-se que o seu número de vendas fosse maior, contudo, as ferramentas para a divulgação dos produtos não possuíam aproveitamento adequado. Durante a pesquisa, esta mesma área demonstrou ser a mais crítica, principalmente quanto aos critérios de conversão e acompanhamento 
dos resultados. Sendo assim, iniciou-se a composição do marketing digital para o aumento da captação de clientes e lucratividade no ascendimento desta $e$ commerce.

Vendo que o marketing necessita de atenção, trabalha-se em cima de uma questão norteadora, que é capaz de delimitar a área trabalhada e visa: Como o marketing digital e de conteúdo podem ser importantes no aumento de clientes e lucratividade de uma e-commerce em ascensão?

A partir disto, a metodologia é desenvolvida como forma de nortear a pesquisa, onde para isso foi utilizado um estudo bibliográfico que possui finalidade estratégica, apresentando bases teóricas e práticas que possibilitam o estudo para os demais pesquisadores. Assim, quantos aos seus objetivos, declara-se uma pesquisa descritiva que poderá ser utilizada por demais e-commerces.

Portanto, determinou-se as estratégias de marketing mais viáveis para o ambiente web, em busca do aumento do consumo de produtos eróticos nas plataformas digitais para expandir o engajamento e a lucratividade baseada no marketing digital.

Desta forma, somando esse conjunto de ferramentas obteve-se uma pesquisa capaz de alavancar a captação e lucratividade de uma empresa ativa em um mercado extremamente competitivo, que através de ações interventivas alcançou os resultados esperados.

\section{FUNDAMENTAÇÃO TEÓRICA}

\subsection{EVOLUÇÃO DO MARKETING}

Não é novidade que a globalização, as oscilações no cenário econômico, e as descobertas tecnológicas, trazem grandes mudanças ao mercado, e por consequência, o marketing adquire novos pensamentos, passando assim por uma evolução. 
De acordo com Silva (2015, p. 29), as antigas empresas eram direcionadas ao marketing de massa, ou seja, o objetivo era atingir qualquer cliente. Já as atuais possuem relacionamentos mais duradouros e por isso selecionam seus clientes e os tratam de forma mais direta.

Dessa forma, o marketing tende a formar conexões mais satisfatórias e de valor tanto com o cliente quanto com os seus parceiros, fornecedores e mercados internos e externos, focando em relacionamentos lucrativos, engajando todos os setores para um mesmo objetivo e selecionando mercados em potencial sem esquecer das causas mundiais que conduzem a economia, como as responsabilidades sociais e ambientais.

Ferreira Junior (2015) deixa claro que através das ferramentas digitais, é possível analisar e conhecer as necessidades dos clientes a fim de tornar a empresa atrativa e com boa reputação, o que consequentemente irá trazer maior visibilidade e lucro. Reafirmando que o marketing do momento é tecnológico.

\subsubsection{OS 4P'S DO MARKETING}

Os pilares do marketing relacionados aos $4 \mathrm{P}$ 's são ligados a uma estratégia de planejamento que, quando feita de forma assertiva, produz efeitos categóricos, dentro do marketing proposto para a retenção e captação de clientes e sucesso da marca comercializada.

Conforme bem coloca Rocha (2015, p. 150), os 4 P's possuem um direcionamento unilateral, ou seja, a decisão fica centralizada a empresa, havendo pouca influência por parte do cliente, e, por isso, este segue uma estrutura mercadológica formada a partir do produto, do preço, da praça e da promoção.

Logo, são ferramentas eficientes para fortalecer uma marca no mercado e alavancar as vendas nas empresas. Ignorar esses pilares, e encarar o mercado apenas com ideias mal idealizadas, levará uma empresa ao fracasso de forma atípica e rápida,

RC: 102101

Disponível em: https://www.nucleodoconhecimento.com.br/administracao/captacaode-clientes 
assim, para manter-se de forma assertiva esta deve buscar pesquisas e análises de mercado para tomadas de decisões e norteamento do seu futuro comercial.

Brito (2013, p. 21) deixa claro que produto, praça, preço e promoção formam a estratégia necessária para a obtenção do melhor resultado possível. Sendo assim, uma empresa deve buscar a melhor estratégia, entendendo sempre o meio ao qual se encaixa.

\subsubsection{MARKETING DIGITAL}

Com a evolução da internet, há o crescimento de uma nova vertente do marketing, que se difere bastante do tradicional, chamado marketing digital, o qual dispõe de características como: qualidade de conteúdo, conexão direta e personalizada com o cliente, segmentações específicas, facilidade no rastreamento dos resultados, acessibilidade por causa do ambiente web em que está inserido, e interatividade, o que faz a marca torna-se cada vez mais popular e com respostas mais rápidas tanto para o consumidor final quanto para a empresa.

Para Farias (2015, p. 19), este escopo do marketing está em constante mudança, pois a interação que ocorre dentro da internet, principal meio onde o marketing digital está inserido, dá-se de forma muito rápida. Desta forma, nele também se nota grande concorrência, devido a velocidade e a facilidade que os clientes possuem em obter informações sobre outros produtos, empresas ou serviços.

Ainda que desafiador, o marketing digital é o meio que possibilita o crescimento mais rápido de e-commerces ou empresas em fase de iniciação, e auxiliam na divulgação do seu conteúdo e/ou marca. Portanto, todas as oportunidades que este escopo traz para o marketing agregam mudança nos processos de compra, um exemplo é o valor oferecido para o consumidor, que possui um leque de opções, e procura nas mídias sociais o que mais the atende.

Contudo, Kotler (2017) enfatiza o famoso marketing 4.0 dizendo o que deve permanecer constante dentro do marketing da empresa, sendo estes a

RC: 102101

Disponível em: https://www.nucleodoconhecimento.com.br/administracao/captacaode-clientes 
personalidade e o código da marca, já os demais setores devem se tornar mais dinâmicos para que consigam enfrentar as numerosas situações em diferentes parâmetros que irão aparecer, pois atualmente a comunicação sistemática e repetitiva não é mais eficiente.

\subsubsection{ESTRATÉGIA DE CONTEÚDO}

Esta estratégia não visa apenas fazer a divulgação dos produtos/serviços para o consumidor, pelo contrário, como seu próprio nome diz, a mesma vem tornando-se cada vez mais procurada por gerar conteúdo de qualidade, o que atrai o público-alvo e potenciais clientes, gera credibilidade, confiabilidade e vantagem competitiva sobre a concorrência e influência na assertividade para o fechamento das vendas.

Os autores atuais reconhecem a grandiosidade dessa estratégia, Novaes (2021, p. 12) por exemplo, declara que as empresas estão investindo cada vez mais em conteúdo, por terem a convicção de que apenas redatores com boa gramática, não são capazes de alavancar suas vendas, mas se aplicarem estratégias de marketing ao conteúdo, produzindo relevância a este e propagando ideias consumíveis, as publicações serão a peça-chave para se destacarem no mercado.

A interatividade é uma ferramenta importante para o marketing de conteúdo, uma vez que a persona do cliente consegue ser melhor definida através dos feedbacks recebidos nos quizzes, nas enquetes, e até mesmo nas curtidas e comentários, que podem ser positivos ou negativos.

De forma mais dinâmica, o cliente sente-se estimulado a experimentar os produtos no conteúdo divulgado, gerando o engajamento/reconhecimento da empresa, atraindo leads e otimizando as conversões devido ao aumento de acessos.

Segundo Brito (2013, p. 101), é necessário a interação com o cliente, com o intuito de descobrir e entender suas necessidades, a fim de personalizar ao máximo seu produto ou serviço, até que este seja o real desejo do consumidor.

RC: 102101

Disponível em: https://www.nucleodoconhecimento.com.br/administracao/captacaode-clientes 


\subsubsection{MENSURAÇÃO DE RESULTADOS}

Entender seus passos, seu desenvolvimento e acompanhar seu engajamento e aceitação no mercado são benefícios que a estratégia do marketing de conteúdo é capaz de fornecer. Toda essa mensuração de resultados determina se o conteúdo que está sendo oferecido, consegue atingir os objetivos da empresa e principalmente o seu crescimento de público-alvo.

Para Kotler (2017), existem algumas categorias que definem se o conteúdo é: assimilado, medindo a quantificação do alcance e das impressões das personas; comunicável, para entender o quão bem este pode atrair interesses, como se aumentou o número de visitas das páginas ou até mesmo as taxas de rejeição da marca; pesquisável, descobrindo como o conteúdo é descoberto através dos mecanismos de busca e suas referências; útil, rastreando se o conteúdo consegue induzir o cliente a realizar a ação, um exemplo são as taxas de cliques no conteúdo e de conversão; e apologia, que implica no quanto o conteúdo é compartilhável e nas taxas de seu engajamento.

Focar na mensuração dos resultados, implica em conhecer o retorno sobre os investimentos e vendas, geralmente apresentado através de relatórios que mostram o que é necessário ser feito para que a empresa continue a evoluir. É analisando resultados que se chega no objetivo final, pois estes são capazes de gerar Leads, oportunidades de negócios, que se bem trabalhados em cima das mensurações descobertas, são redirecionadas a vendas e lucratividades.

Segundo Peçanha (2017, p. 09), o marketing digital diferencia-se por conseguir mensurar os leads, tornando-os cada vez mais qualificados comercialmente, o que resulta na diminuição considerável de custos e no aumento da eficiência destes. Algumas informações coletadas durante a análise dos resultados nos leads conseguem dizer muito sobre o perfil de cliente da empresa, como informações demográficas e comportamentais.

RC: 102101

Disponível em: https://www.nucleodoconhecimento.com.br/administracao/captacaode-clientes 
Portanto, fazer o acompanhamento de seus resultados num mercado tão competitivo, torna-se indispensável para o crescimento de uma e-commerce em ascensão. E apesar de, no último ano, este nicho ter tido um grande aumento, o diferencial daquelas que conseguem destacar-se é justamente o conhecimento dos dados da sua empresa, e o relacionamento direto que obtém com o consumidor.

\section{MATERIAIS E MÉTODOS}

Para Bazzanella (2013, p. 65) o método possui três definições, podendo ser um processo racional com seguimento para alcançar o fim, uma forma sistemática de proceder ou um conjunto de ações técnicas e científicas.

Sendo assim, segundo Zambello (2018, p. 55), o método pode ser dedutivo com um trajeto definido que parte de percepções mais gerais, onde são examinados casos mais particulares, verificando se podem ou não se enquadrar nas informações mais gerais.

Logo, o método aqui utilizado, trata-se do dedutivo, pois enumera-se os fatos e argumentos sobre a empresa, partindo da hipótese e dedução de maior premissa, unindo a uma premissa menor e comum às demais e-commerces, gerando uma conclusão, através do raciocínio lógico.

\subsection{PROCEDIMENTOS METODOLÓGICOS}

É possível definir qual tipo de pesquisa está sendo feito, através de seus procedimentos metodológicos, Carvalho et.al (2019, p. 36) explica que uma pesquisa pode ser classificada conforme será feita a sua coleta de dados, havendo então uma dicotomia entre escolher trabalhar com opiniões de artigos ou objetos de pesquisas já publicados, ou tratar dados fornecidos por pessoas.

Posto isso, foi adotado o método bibliográfico que possui vertentes em pesquisas, como citam Marconi e Lakatos (2017, p. 34), que se baseiam em livros e artigos, 
sendo estas referências que podem auxiliar de forma mais abrangente o conteúdo já publicado, tendo vários tipos de textos para se buscar o conhecimento.

Dessa forma, o material desse artigo, está pautado em buscas de autores que possuem métodos e informações que auxiliem a proposta de melhoria que foi definida e que será vista nos próximos tópicos de conceituação.

\subsubsection{QUANTO À NATUREZA}

Para Pereira (2018, p. 67), a base estrutural deste tipo de pesquisa deve ser a compreensão do que está sendo estudado e levantado para que todo o contexto faça sentido quando os pontos forem expostos.

Já Rauen (2015, p. 164) chama as pesquisas de investigações, uma vez que são realizadas entrevistas envolvendo verdades e informações locais, que irão designar de que forma os resultados obtidos serão aplicados na prática, ocorrendo assim a resolução do problema.

Para tanto, a ferramenta mais comum para esse levantamento de dados é a entrevista, uma vez que através dela é possível que o pesquisador consiga ter um dimensionamento dos temas e das questões a serem abordadas, obtendo o resultado para seu estudo.

\subsubsection{QUANTO AOS FINS}

Segundo Appolinário (2012, p. 62), ligada aos objetivos que os pesquisadores possuem, a pesquisa básica está voltada para promover o conhecimento científico sem qualquer objetivo comercial.

Seguindo este mesmo pensamento Oliveira (2019) define que a pesquisa básica é pautada na revisão bibliográfica, com a finalidade de contribuir com o estudo de um determinado tema, e quando esta é classificada como básica estratégica, o seu foco 
passa a ser não somente um conhecimento útil, mas a utilizar todo o estudo prático adquirido durante a pesquisa.

Portanto, este artigo produz um conhecimento útil a fim de que ele seja usado como base para estudos que o coloquem em prática, com o intuito de desenvolver hipóteses, que irão auxiliar no crescimento de uma instituição como, no caso, uma $e$ commerce em estado de ascensão.

\subsubsection{QUANTO AOS MEIOS}

Aragão (2017, p. 27) pontua que é necessário que a abordagem tenha acompanhamento de pesquisa minuciosa no tema do problema, pois dessa forma o processo torna-se mais compacto e com maior celeridade, visto que os temas estarão diretamente adequados.

Já para Carvalho et.al (2019, p. 34), este tipo de pesquisa aprimora e permite que o pesquisador aperfeiçoe o seu conhecimento de tal forma que, no final desta, outras pesquisas consigam ser criadas com novas abordagens, é devido a isso, que em sua maioria, as pesquisas exploratórias são ligadas a estudos bibliográficos.

Logo, a pesquisa descritiva bem se encaixa neste artigo apresentado, por sua linha de exposição bibliográfica, e por estar voltada a ser um estudo que ajudará ecommerces a se destacarem no mercado online que é altamente competitivo.

\subsection{CARACTERÍSTICAS DA EMPRESA}

A Hot Secrets, empresa de vendas de produtos eróticos, foi fundada em 16 de setembro de 2020, por Gustavo Didier. Ao observar a necessidade de levar conhecimento e descobertas, a empresa foi criada com a finalidade de vender produtos e serviços eróticos, com pontos estratégicos de vendas digitais, onde os clientes eram atendidos através de catálogo online e da plataforma Instagram, nascendo assim um novo modal de vendas.

RC: 102101

Disponível em: https://www.nucleodoconhecimento.com.br/administracao/captacaode-clientes 
Atualmente, a empresa consta como serviço principal a atividade de representação e serviços de qualquer natureza, inclusive comércio, e nas atividades secundárias, consta o comércio atacadista e varejista de produtos em geral.

A Hot Secrets, que é uma empresa Eireli (único sócio com responsabilidade limitada), possui em seu quadro de funcionários, 5 colaboradores em regime de CLT. O setor comercial funciona no horário das 09:00 hs às 18:00 hs, com intervalo de almoço.

\section{RESULTADO E DISCUSSÕES}

Mediante os dados coletados com o objetivo de obter informações sobre um setor específico que necessitava de intervenções para um aumento significativo na captação de clientes da e-commerce, observou-se através da estrutura qualitativa, que a área de desempenho de Marketing precisava de ajustes.

Conforme o gráfico abaixo.

Gráfico 01: Medição de desempenho.

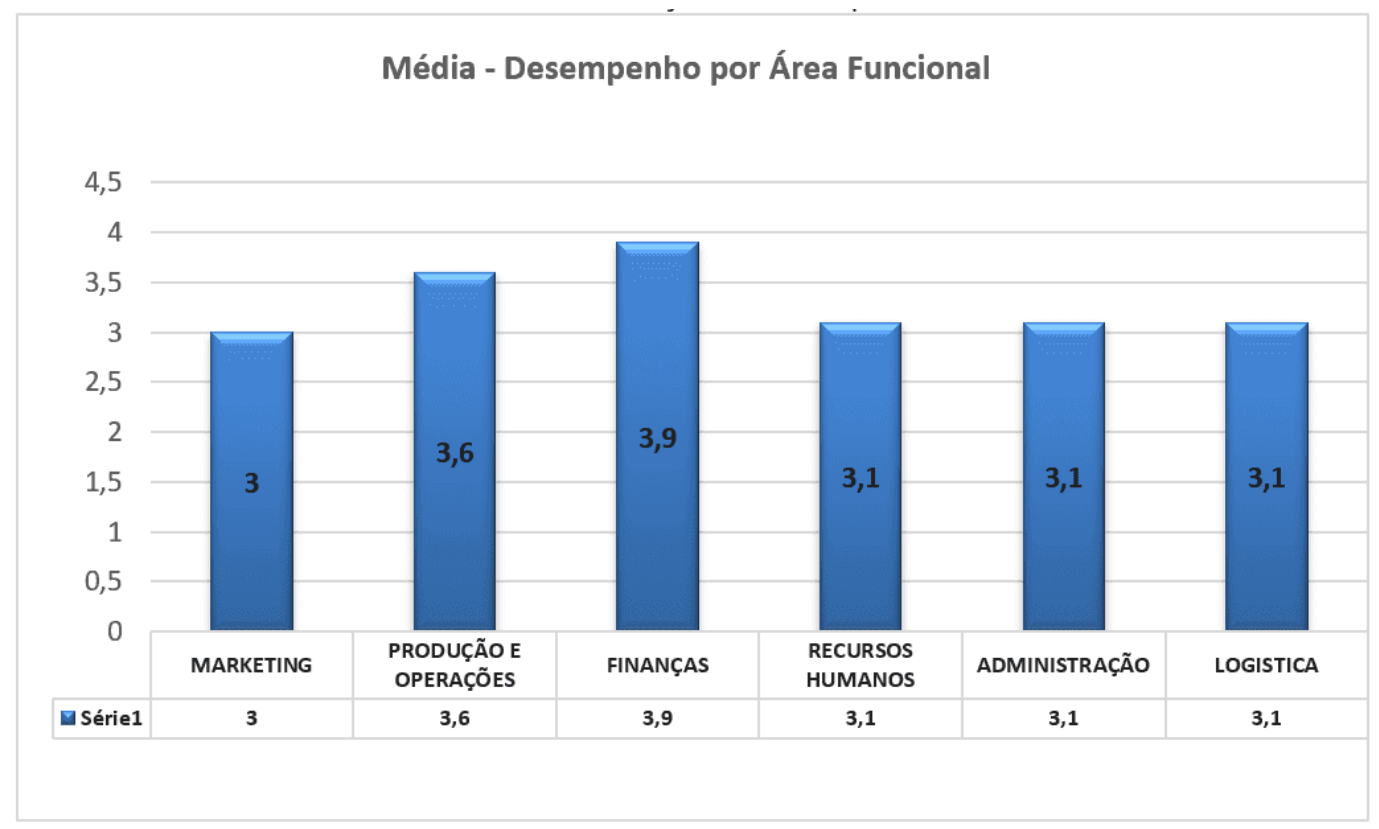

Fonte: Elaborado pelos autores com base na coleta de dados (2021).

RC: 102101

Disponível em: https://www.nucleodoconhecimento.com.br/administracao/captacaode-clientes 
Foi possível identificar que alguns setores como o de finanças e produção de operações, possuem uma média acima das demais, dentre os requisitos e vertentes de avaliação aplicados que muito se difere da área de Marketing.

Quadro 01: Marketing

\begin{tabular}{|c|c|c|c|c|c|c|}
\hline \multicolumn{2}{|c|}{ ÁREA FUNCIONAL } & \multicolumn{5}{|c|}{ NÍVEL OU GRAU DE AVALIAÇÃO } \\
\hline \multicolumn{2}{|c|}{ MARKETING } & Ponto & Ponto & Ponto & Ponto & Ponto \\
\hline 1 & $\begin{array}{l}\text { Evidenciou-se vasta segmentação } \\
\text { dos produtos eróticos }\end{array}$ & $\mathrm{X}$ & & & & \\
\hline 2 & $\begin{array}{l}\text { Construiu-se políticas estruturadas } \\
\text { de promoções }\end{array}$ & & & & $\mathrm{X}$ & \\
\hline 3 & $\begin{array}{l}\text { Destaca-se a plataforma de e- } \\
\text { commerce processo otimizado de } \\
\text { buscas }\end{array}$ & & $X$ & & & \\
\hline 4 & $\begin{array}{l}\text { Coletam-se informações sobre ticket } \\
\text { médio de vendas }\end{array}$ & & & & $x$ & \\
\hline 5 & $\begin{array}{l}\text { Verifica-se comunicação visual de } \\
\text { qualidade, criativa e inovadora }\end{array}$ & & $\mathrm{X}$ & & & \\
\hline 6 & $\begin{array}{l}\text { Agrupam-se os dados de tráfego no } \\
\text { site }\end{array}$ & & & & & $\mathrm{X}$ \\
\hline 7 & Avalia-se a taxa de conversão & & & & & $\mathrm{X}$ \\
\hline 8 & $\begin{array}{l}\text { Avalia-se taxa de rejeição / } \\
\text { abandono de carrinho }\end{array}$ & & & $\mathrm{X}$ & & \\
\hline 9 & $\begin{array}{l}\text { Controla-se } 0 \text { tempo de } \\
\text { processamento de pedidos }\end{array}$ & & & $\mathrm{X}$ & & \\
\hline 10 & $\begin{array}{l}\text { Propaganda dos produtos incentiva } \\
\text { o processo de compra }\end{array}$ & $\mathrm{X}$ & & & & \\
\hline
\end{tabular}

RC: 102101

Disponível em: https://www.nucleodoconhecimento.com.br/administracao/captacaode-clientes 


\begin{tabular}{|l|l|l|l|l|l|}
\hline TOTAL $(\Sigma)$ & 10 & 8 & 6 & 4 & 2 \\
\hline MÉDIA POR GRAU (POR COLUNA) & 1 & 0,8 & 0,6 & 0,4 & 0,2 \\
\hline DESEMPENHO DA ÁREA $(\Sigma)$ TOTAL & 3 & & & & \\
\hline
\end{tabular}

Fonte: Elaborados pelos autores (2021)

De acordo com o levantamento apresentado é possível compreender que uma estratégia de marketing má gerenciada ou não aplicada de forma assertiva e eficiente implica diretamente no baixo crescimento de qualquer nicho de mercado, ainda mais sendo uma e-commerce que é uma modalidade de negócio online, onde a busca por esse tipo de mercado possui uma propagação de anúncios. Estratégias de marketing fazem toda a diferença.

Considerando os fatores indicados pelo nível ou grau de avaliação, foi necessário o uso de ações para melhor propor a resolução da questão problema abordada pelos pesquisadores: Como o marketing digital e de conteúdo podem ser importantes no aumento de clientes e lucratividade de uma e-commerce em ascensão? Assim melhorando o gerenciamento no setor e atingindo os objetivos.

\subsection{PLANEJAMENTO DAS AÇÕES}

Para maximizar os ganhos com o marketing, foi necessário o uso de ações interventivas que possuem o objetivo de propor alternativas que melhoram a estrutura do setor que apresenta déficit baixo. Essas ações são voltadas ao nível de desempenho.

Quadro 02: Ações interventivas.

\begin{tabular}{|l|l|l|l|l|}
\hline 01 & Ações Interventivas & Cronologia & Duração & Custo \\
\hline $\begin{array}{l}\text { Elaborar Hotsite/micro site } \\
\text { para aumentar alcance de } \\
\text { engajamento e promoções. }\end{array}$ & & Setembro/2021 & 15 dias & $\mathrm{R} \$ 1.090,00$ \\
\hline
\end{tabular}


possível executar ações de acordo com o que se é proposto inicialmente apenas desenhando o objetivo final.

\subsubsection{ELABORAR HOTSITE/MICROSITES PARA AUMENTAR O ALCANCE DE ENGAJAMENTO E PROMOÇÕES}

É importante identificar as oportunidades que a tecnologia oferece diante das renovações que o mercado e a internet proporcionam. A criação de sites, também chamados de microsites, podem viabilizar e intensificar uma promoção ou campanhas como Black Friday, por exemplo. Como funcionam com uma data de término podem conduzir um engajamento diante de um tema erótico de forma expressiva e captadora de clientes.

Quadro 03: 5WH2 - Elaborar Hotsite/microsite para aumentar alcance de engajamento e promoções

Elaborar Hotsite/microsite para aumentar alcance de engajamento e promoções

\begin{tabular}{|l|l|}
\hline O que? & Elaborar hotsite \\
\hline Por quê? & Aumentar o engajamento e promoções \\
\hline Onde? & Em um hotsite - inserido no ambiente Google \\
\hline Quando? & $\begin{array}{l}\text { Setembro/2021 ou em qualquer campanha promocional ou data } \\
\text { comemorativa exemplo: dia do sexo 06/09 }\end{array}$ \\
\hline Quem? & Setor de Marketing \\
\hline Como? & Através de assessoria como: sympla, high sales \\
\hline Quanto? & $\mathrm{R} \$ 1.090,00$ \\
\hline
\end{tabular}

Fonte: Elaborado pelos autores (2021)

Implementar o Hotsite, é uma alternativa que gera lucros a curto prazo, com grande visualização e a baixo custo, uma vez que é possível disponibilizar os produtos que estão no estoque há tempos ou que possuem sua data de validade próxima ao 
vencimento de forma promocional, gerando visualização do conteúdo e principalmente marca/empresa que o anuncia.

\subsubsection{DESENVOLVER GAMES ERÓTICOS QUE ANUNCIEM A MARCA HOT SECRETS E SEUS PRODUTOS, DISPONIBILIZANDO- OS NAS PLATAFORMAS DE DOWNLOADS GRATUITOS}

Para que a empresa alcance viabilidade e consiga se conectar com seus clientes em potencial, é necessário que as suas estratégias de marketing estejam ligadas ao que há de mais moderno em plataformas digitais, e uma das ações é justamente a implementação e desenvolvimento de games com tema erótico que possam divulgar a marca.

Para alcançar os objetivos foi implantado o desenvolvimento de um game com intenção de aprofundar o relacionamento e propagandear os produtos da loja virtual. Game marketing é uma estratégia que vem crescendo e captando novos clientes e fidelizando os já existentes.

Quadro 04: 5WH2 - Desenvolver Games Eróticos que anunciem a marca Hot Secrets e seus produtos, disponibilizando-os nas plataformas de downloads gratuitos.

Desenvolver Games Eróticos que anunciem a marca Hot Secrets e seus produtos, disponibilizando-os nas plataformas de downloads gratuitos

\begin{tabular}{|l|l|}
\hline O que? & Desenvolver Games \\
\hline Por quê? & Anunciar a marca Hot Secrets e produtos eróticos \\
\hline Onde? & Play Store e Apple Store \\
\hline Quando? & Janeiro/2022 \\
\hline Quem? & Setor de Marketing \\
\hline Como? & Empresa desenvolvedora de software contratada \\
\hline
\end{tabular}

RC: 102101

Disponível em: https://www.nucleodoconhecimento.com.br/administracao/captacaode-clientes 


\section{Quanto?}

$\mathrm{R} \$ 27.880,00$

Fonte: Elaborado pelos autores (2021)

Esta estratégia busca variar o público consumidor de produtos eróticos, pois através dos games, principalmente os gratuitos, é possível lançar uma diversidade de anúncios, incluindo os da marca e produtos, lembrando que, como a classificação interativa desses é acima de 18 anos, todos os consumidores são aptos ao consumo dos serviços divulgados na plataforma. Essa alternativa pode ser acompanhada de bons lucros, porém demanda tempo e custos maiores para o alcance de bons resultados.

\subsubsection{INVESTIR EM AÇÕES DE RESPONSABILIDADE SOCIAL, CONSCIENTIZANDO O PÚBlico ATRAVÉs DE PRODUTOS ERÓTICOS}

Percebe-se que os temas eróticos possuem um elevado aumento de comercialização quando atrelados a campanhas e temas, visando isso a execução das ações de cunho de responsabilidade social como setembro amarelo e dezembro vermelho são oportunidades de intensificar que sexo seguro é saúde.

É favorável que os produtos sejam comercializados de forma responsável tendo também um papel social para com a sociedade. Manter o público informado sobre as ações preventivas faz toda a diferença.

Quadro 05: 5WH2 - Investir em ações de Responsabilidade Social, conscientizando o público através de produtos eróticos.

Investir em ações de Responsabilidade Social, conscientizando o público através de produtos eróticos

O que? Investir em ações de Responsabilidade Social

Por quê? Para conscientização do público-alvo 
Onde? No e-commerce Hot Secrets

Quando? Setembro/2021

Quem? Setor de Marketing

Como? Ministração de palestras, entregas de kits, sorteio interativo, e-mail marketing, lives e podcasts

Quanto? R\$1.000,00

Fonte: Elaborado pelos autores (2021)

As ações de responsabilidade social ocorrem em grandes proporções, uma vez que as empresas de todos os setores também investem nessa estratégia potencial. Desta forma, o mercado erótico também precisa se enquadrar nessas práticas. As campanhas podem ser de baixo custo e ter interatividade através das redes sociais gratuitas, e-mail marketing ou kits de entregas propostos com temas diferenciados, assim, os resultados virão acompanhados do aumento de leads.

\subsubsection{CRIAR CAMPANHAS PARA QUEBRAR TABUS ERÓTICOS COMO: SEXO VS. FÉ; CASAMENTO VS. INOVAÇÃO SEXUAL}

Apesar de toda a desmistificação sobre produtos eróticos dentro da sociedade, verifica-se que ainda é possível visualizar tabus. É importante criar campanhas que venham com slogans fortes que retenham a atenção do público e os façam pensar que as relações sexuais são, de forma geral, um ciclo natural da vida adulta.

É notável que dentro de relações matrimoniais ou casuais ainda existem muitos paradigmas a serem discutidos e essas campanhas têm como objetivo conscientizar e esclarecer fatos que possam agregar valor e liberdade sexual.

Quadro 06: 5WH2 - Criar campanhas para quebrar Tabus eróticos como; sexo vs. fé; casamento vs. Inovação sexual.

Criar campanhas para quebrar Tabus eróticos como; sexo vs. fé; casamento vs. 
Inovação

sexual

\begin{tabular}{l|l}
\hline O que? & Criar campanhas sobre Tabus \\
\hline Por quê? & Desmistificar Tabus Eróticos \\
\hline Onde? & No e-commerce Hot Secrets \\
\hline Quando? & 6 de setembro/2021 \\
\hline Quem? & Setor de Marketing \\
\hline Como? & Criação de conteúdo em feeds, Reels ou podcasts \\
\hline Quanto? & $\mathrm{R} \$ 2.000,00$
\end{tabular}

Fonte: Elaborado pelos autores (2021)

As campanhas de quebra de tabus, é de extrema importância, afinal em pleno século XXI, ainda é difícil falar abertamente de sexo, sem sofrer com denúncias de conteúdo. Portanto, isso não se trata apenas de divulgar a marca, mas também de deixar o mercado mais preparado e informado para receber as inovações do mercado erótico. Os podcasts, por exemplo, com figuras ilustres do sexo, podem gerar um custo elevado, porém terá um engajamento gigantesco por causa dos seus seguidores, dando visibilidade e consequente lucro a empresa.

\subsubsection{ACOMPANHAR A ANÁLISE DE DESEMPENHO DOS CLIENTES EM POTENCIAL DENTRO DAS PLATAFORMAS SOCIAIS}

As mídias ou redes sociais são excelentes ferramentas de otimização de tempo e produzem cada vez mais conteúdos com celeridade. Dessa forma, o acompanhamento da demonstração de alcance se faz essencial para retenção do público-alvo.

Nota-se que a interatividade é o caminho para alcançar os resultados, elaborando proximidade com o conteúdo buscado dentro dessas plataformas. Posto isso, a criatividade precisa ser aplicada de forma coesiva e estruturada. É preciso acompanhar e realizar estratégias de conteúdo.

RC: 102101

Disponível em: https://www.nucleodoconhecimento.com.br/administracao/captacaode-clientes 
Quadro 07: 5WH2 - Acompanhar a análise de desempenho dos clientes em potencial dentro das plataformas sociais.

Acompanhar a análise de desempenho dos clientes em potencial dentro das plataformas sociais

O que? Acompanhar a análise de desempenho de possíveis clientes

Por quê? Captação de novos clientes

Onde? Plataformas de redes sociais

Quando? Setembro/2021

Quem? Setor de Marketing

Como? Através de painel profissional como o business intelligence (BI)

Quanto? R\$500,00

Fonte: Elaborado pelos autores (2021)

Se faz necessário o acompanhamento dentro das principais plataformas sociais para alavancar resultados de possível clientes, as ferramentas utilizadas são de extrema importância para dimensionar o que o público está buscando, como a descrita acima que é muito utilizada no mercado, adquirida para projetar de forma ampla e profissional a captação de novos entrantes no ramo erótico.

\subsubsection{ACOMPANHAR OS INDICADORES CHAVES DE PERFORMANCE DENTRO DAS CAMPANHAS DE VENDAS E PUBLICIDADE}

Para aumentar as vendas os indicadores precisam ser estudados e interpretados como oportunidades de crescimento, o tráfego digital é uma excelente mensuração de tudo que é vinculado às pesquisas, compras, visitas aos sites.

Pode-se atribuir a gestão de Leads como uma ferramenta de análise de performance, onde são coletadas as informações do cliente em potencial para que seja feito contatos posteriores, alimentando a fonte de dados. Dessa forma, essas

RC: 102101

Disponível em: https://www.nucleodoconhecimento.com.br/administracao/captacaode-clientes 
estratégias que a tecnologia proporciona devem ser bem aproveitadas. Mediante todos os pontos citados, os indicadores chaves são indispensáveis e necessários para o alcance do sucesso.

Quadro 08: 5WH2 - Acompanhar os indicadores chaves de performance dentro das campanhas de vendas e publicidade.

Acompanhar os indicadores chaves de performance dentro das campanhas de vendas e publicidade

\begin{tabular}{|l|l|}
\hline O que? & Acompanhar os indicadores chaves de performance \\
\hline Por quê? & Gerenciar os resultados de performance \\
\hline Onde? & No e-commerce Hot Secrets \\
\hline Quando? & Setembro/2021 \\
\hline Quem? & Setor de Marketing \\
\hline Como? & Extração e acompanhamento de relatórios de Tráfego digital \\
\hline Quanto? & $\mathrm{R} \$ 2.000,00$ \\
\hline
\end{tabular}

Fonte: Elaborado pelos autores (2021)

A aplicação do tráfego digital nessa proposta de melhoria objetiva estabelecer um parâmetro de coleta de dados, os quais servirão como um termômetro de vendas, assim, se analisados de forma assertiva são capazes de impulsionar as vendas, direcionando-as a uma melhor aplicação do marketing.

O acompanhamento deve ser contínuo para aprimorar os resultados, pois estes serão os grandes responsáveis para o aumento dos lucros e a mensuração do reconhecimento da marca no mercado, que está em constante evolução.

\section{CONSIDERAÇÕES FINAIS}

Dada a exposição dos fatos e fatores apresentados durante todo o procedimento de pesquisa aplicado dentro de uma e-commerce em ascendimento, foi possível denotar aspectos importantes para a proposta de utilização do marketing digital na

RC: 102101

Disponível em: https://www.nucleodoconhecimento.com.br/administracao/captacaode-clientes 
captação de clientes em um ramo que possui grande amplificação na sociedade moderna, o ramo erótico.

Para resolver este estudo de caso, levantou-se a seguinte questão: Como o marketing digital e de conteúdo podem ser importantes no aumento de clientes e lucratividade de uma e-commerce em ascensão? Logo, os resultados alcançados estão visíveis dentro das ações interventivas, que contribuem para maior engajamento da marca, elevação no número de leads e lucros melhores pela alta demanda de vendas. Com base em pesquisa qualitativa foram apontados pontos fracos, e assim desenvolvidas ações que pudessem intervir para atingir o objetivo geral de compor o marketing de conteúdo, elevando a lucratividade e, claro, almejando crescimento de clientes e comercialização de produtos da Hot Secrets.

Levando-se em consideração a estrutura delimitada de melhoria, baseada na ferramenta de qualidade $5 \mathrm{~W} 2 \mathrm{H}$ foi possível perceber que as estratégias baseadas em ações criadas e aplicadas são pertinentes com o preenchimento do déficit encontrado e projeção de ganhos a partir da implementação.

Mediante aos resultados da pesquisa, é notório que se as estratégias de marketing digital que abrangem vertentes agregadoras no novo milênio forem aplicadas de forma assertiva e com conteúdo interativo, estas podem atingir todos os gêneros como bem explícitos na proposta de melhoria deste artigo.

Dessa forma, a proposta de melhoria da área de marketing da e-commerce favorece tanto o proprietário que pode aplicar as ações interventivas propostas, quanto as novas lojas virtuais nesse mesmo modelo de segmento digital. A pesquisa proporcionou análises de métodos, desenvolvimentos de estratégias de marketing e como as plataformas digitais podem ser aliadas no sucesso de um nicho de mercado.

\section{REFERÊNCIAS}

RC: 102101

Disponível em: https://www.nucleodoconhecimento.com.br/administracao/captacaode-clientes 
APPOLINÁRIO, F. Metodologia da ciência: filosofia e prática da pesquisa. 2. ed. São Paulo: Cengage Learning, 2012.

ARAGÃO, J. W. M. de.; NETA, M. A. H. M. Metodologia Científica. Salvador: UFBA, Faculdade de Educação, Superintendência de Educação a Distância, 2017.

BAZZANELLA, A. et al. Metodologia científica (Org.). Indaial: Uniasselvi, 2013.

BRITO, A. L. S. Fundamentos de Marketing. Aracaju: UNIT, 2013.

CARVALHO, L. O. R. et al. Metodologia Científica: teoria e aplicação na educação a distância. Petrolina, PE 2019.

FARIAS, C. et al. Marketing Aplicado. Porto Alegre: Bookman, 2015.

FERREIRA JUNIOR, A. B.; AZEVEDO, N. Q. de. Marketing Digital: Uma Análise De Mercado 3.0. 1를 Edição. Curitiba: InterSaberes, 2015.

KOTTLER, P. et al. Marketing 4.0: Mudança do tradicional para o digital. Coimbra, Portugal: Conjuntura Actual Editora, 2017.

MACHADO, S. S. Gestão da qualidade. Inhumas: FG; Santa Maria: Universidade Federal de Santa Maria, 2012.

MARCONI, M. de A.; LAKATOS, E. M. Fundamentos de metodologia científica. 8. ed. São Paulo: Atlas, 2017.

NOVAES, H. Marketing de Conteúdo: Tudo o que você precisa saber para se tornar um webwriter profissional e alavancar seu negócio com conteúdos poderosos. Editora Bibliomundi, 30 de junho de 2021, p.136.

OLIVEIRA, A. C. de. Classificação de finalidade em pesquisa acadêmica. Atena Editora, 15 de julho de 2019. Disponível em://atenaeditora.com.br/blog/classificaçaode-finalidade-em-pesquisa-academico/. Acesso em: 27 de julho de 2021.

RC: 102101

Disponível em: https://www.nucleodoconhecimento.com.br/administracao/captacaode-clientes 
PEÇANHA, V. Obrigado pelo marketing: Um guia completo de como encantar pessoas e gerar negócios utilizando o marketing de conteúdo. São Paulo: Benvirá, 2017.

PEREIRA, A. S. et al. Metodologia da pesquisa científica. 1. ed. Santa Maria, RS, 2018.

RAUEN, F. J. Roteiros de iniciação científica: os primeiros passos da pesquisa científica desde a concepção até a produção e a apresentação. Palhoça: Editora Unisul, 2015.

ROCHA, R. A. da.; PLATT, A. A. Administração de Marketing. 3. ed. Florianópolis: Departamento de Ciências da Administração, 2015.

SILVA, L. A. Administração de Marketing. 1. ed. Rio de Janeiro: Copyright SESES, 2015.

ZAMBELlO, A. V. et al. Metodologia da pesquisa e do trabalho científico. Penápolis: FUNEPE, 2018.

Enviado: Outubro, 2021.

Aprovado: Novembro, 2021. 